\title{
Sistem Informasi Ekspedisi Pengiriman Paket dan Dokumen Berbasis Web Menggunakan PHP dan MySQL Pada PT. Kerta Gaya Pusaka
}

\author{
Nike Wijayanti ${ }^{1}$ \& Heri Abijono ${ }^{2}$ \\ Sekolah Tinggi Teknologi Cahaya Surya Kediri \\ Sekolah Tinggi Teknologi Cahaya Surya Kediri \\ E-mail: ${ }^{1}$ Nicke.wijayanti01@gmail.com, ${ }^{2}$ ahabijono@gmail.com
}

\begin{abstract}
ABSTRAK
Tugas akhir ini merancang sistem tracking ekspedisi pada Kerta Gaya Pusaka yang bermanfaat untuk pengguna, agar dapat menawarkan dan menyebarkan informasi yang baik dengan mudah dan cepat serta dapat memberikan inspirasi kepada pembaca untuk mengetahui informasi ekspedisi termudah. Pembuatan sistem tracking dilakukan dengan menggunakan pemrograman website sehingga memudahkan pengguna dalam mendapatkan informasi. Metode penelitian yang digunakan berdasarkan informasi secara langsung dan akurat, sehingga dapat memperoleh sasaran yang tepat bagi pengguna. Perancangan sistem menggunakan bahasa pemrograman PHP dan database MySQL yang dipublikasikan dari hosting online sebagai editor dan domain berbayar sebagai alamat website. Hasil yang diharapkan dapat diperoleh secara tepat sasaran bagi pengguna. Sehingga website ekspedisi menjadi salah satu praktik terbaik dalam pengembangan ilmu
\end{abstract}

Kata Kunci : Sistem tracking, informasi, website, online, Sistem Informasi. 


\begin{abstract}
This final project designed an expedition tracking system at Kerta Gaya Pusaka which is useful for users, in order to be able to offer and disseminate good information easily and quickly and can inspire readers to find out the easiest expedition information. Making a tracking system is done by using website programming so that it makes it easier for users to get information. The research method used is based on information directly and accurately, so that it can get the right target for the user. The system design uses the PHP programming language and MySQL database which are published from hosting online as editors and the paid domain as the website address. The expected results can be obtained precisely for the user. So that the expedition website is one of the best practices in the development of science
\end{abstract}

Key words : Tracking systems, information, websites, online, Information Systems 


\section{PENDAHULUAN}

Di era ekonomi saat ini kebutuhan akan transportasi sangat penting. Begitu juga dengan pengiriman barang, menumbuhkan pula persaingan bisnis yang semakin tajam. Dalam hal pengiriman barang baik ke luar negeri maupun dalam negeri, jasa kurir memegang peranan yang sangat penting. Dengan menggunakan jasa kurir, barang yang dikirimkan akan cepat sampai dan dalam kondisi yang baik dari pada dengan melakukan sendiri pengiriman barang. Perusahaan maupun perorangan telah banyak yang menggunakan jasa kurir untuk mengirimkan barang baik dalam jumlah yang kecil maupun besar.

PT. Kerta Gaya Pusaka adalah perusahaan yang bergerak di bidang pengiriman barang yakni menawarkan jasa ekspedisi pengiriman paket dan dokumen yang melalui jalur darat yang wilayah pemasarannya mulai dari pulau jawa sampai luar jawa. Dalam melakukan kegiatan sehari-hari pada bagian ekspedisi pengiriman paket dan dokumen

Tujuan yang ingin dicapai dalam sistem Informasi ekspedisi pengiriman paket dan dokumen pada PT. Kerta Gaya Pusaka ini adalah :

1. Membuat sistem informasi ekspedisi pengiriman paket dan dokumen dengan berbasis web menggunakan system database MySQL untuk mempermudah pelanggan memperoleh informasi pada PT. Kerta Gaya Pusaka secara on line dan akurat.

2. Membuat program sistem informasi yang terbentuk dapat melacak nomor resi dengan keberadaan paket dan dokumen pada PT. Kerta Gaya Pusaka.

3. Membuat program sistem informasi yang terbentuk dapat mengetahui jumlah biaya pengiriman paket dan dokumen pada PT.Kerta Gaya Pusaka.

Hasil dari penelitian ini diharapkan dapat memberikan manfaat khususnya bagi ekspedisi pengiriman paket dan dokumen pada kerta gaya pusaka dan pelanggan antara lain :

1. Memberikan kenyamanan kepada pelanggan dalam mencari informasi tentang pengiriman paket dan dokumen pada PT. kerta gaya pusaka.

2. Memberikan kenyamanan kepada pelanggan dalam mencari informasi tentang melacak nomor resi dengan keberadaan paket dan dokumen pada PT. kerta gaya pusaka. 
3. Memberikan kenyamanan kepada pelanggan dalam mencari informasi tentang jumlah biaya pengiriman paket dan dokumen pada PT. kerta gaya pusaka.

Agar pembahasan lebih terarah, maka ruang lingkup pembahasan hanya pada perancangan sistem yang mencakup pemberian informasi kepada pelanggan jasa ekspedisi mengenai cek jumlah biaya pengiriman dan cek nomor resi keberadaan barang yang dapat diakses melalui Website, dengan data-data yang digunakan antara lain :

1. Sistem informasi ekspedisi pengiriman paket dan dokumen pada PT. Kerta Gaya Pusaka bersifat online.

2. Admin dapat menginputkan data nomor resi, biaya pengiriman paket dan dokumen yang berdasarkan berat barang dengan satuan gram, dan menginputkan data pengiriman pelanggan.

3. Sistem informasi yang digunakan berbasis web dengan menggunakan bahasa PHP dan MySQL.

Penelitian terdahulu sangat penting guna menemukan titik perbedaan maupun persamaan dengan penelitian yang akan dilakukan. Selain itu, penelitian. terdahulu juga berguna sebagai perbandingan sekaligus landasan dalam penelitian tersebut. Penulis menggunakan tiga jurnal penelitian yaitu Perancangan Sistem Informasi Jasa Pengiriman Barang Berbasis Web perancangan sistem informasi pengiriman barang yang dibuat adalah membuat sebuah sistem informasi jasa pengiriman barang dan memberikan pengenalan, pemahaman tentang pembuatan aplikasi jasa pengiriman barang. Peneliti menghasilkan dapat melakukan login, atau memonitoring keberadaan barang pada saat pengiriman berlangsung. Tercapainya tujuan utama dalam penelitian pembuatan aplikasi jasa pengiriman barang.[1] Penelitian juga dilakukan, tentang Sistem informasi pengiriman barang berbasis web dengan metode transshipment yang dibuat adalah Guna menunjang kegiatan operasional pengiriman barang yang ada di PCP cargo cabang tanjung pinang dan meningkatkan efektifitas dan efisiensi yang akhirnya akan meningkatkan pelayanan ke pelanggan. Peneliti menghasilkan informasi pengriman dalam bentuk web, tingkat pelayanan terhadap konsumen atau pelanggan menjadi jauh lebih baik.[2] Penelitian juga dilakukan tentang Sistem Informasi Logistik Untuk Perusahaan Ekspedisi PT. Rajawali Imantaka Sempurna yang dibuat adalah Program aplikasi berbasis web untuk membantu PT. RISE dalam menangani proses 
administrasi yang meliputi pembuatan dokumen pengiriman barang dan sinkronisasi data antar kantor pusat (Mataram) dan kantor cabang (Surabaya). Peneliti menghasilkan kemudahan pada PT. RISE dalam administrasi dokumen antar cabang yang sebelumnya hanya manual belum online website.[3] Teori yang Dipakai untuk menyelesaikan semua masalah dalam penelitian ini seperti Sistem Informasi berbasis web dan perancangan sistem yang meliputi context diagram, DFD, dan ERD.

\section{METODE PENELITIAN}

Metode penelitian merupakan metode yang digunakan untuk mengumpulkan data mengenai suatu masalah. Metode penelitian memegang penting dan menentukan keberhasilan dalam suatu penelitian. Penulis dalam penelitian ini menggunakan cara kwalitatif dan deskriptif yaitu dengan cara melakukan observasi dan wawancara ke lokasi cabang PT. Kerta Gaya Pusaka Kediri. Metode Deskriptif dilakukan dengan bertujuan untuk memaparkan atau mendeskriptifkan atau memberi laporan pada pengguna dan pimpinan PT. Kerta Gaya Pusaka dengan membuat program sistem informasi ekspedisi pengiriman paket dan dokumen bedasarkan analisa kebutuhan sistem informasi sebagai bahan membuat rencana pengujiannya.

Sedangkan Metode Kwalitatif dilakukan dengan penelitian yang menggunakan bilangan yang bersifat deskriptif dan cenderung menggunakan analisis yang dilakukan secara deskriptif. Metode Penelitian terbagi menjadi dua yaitu, metode prngumpulan data dan metode analisis perancangan sistem. Metode pengumpulan data menjelaskan tentang metode observasi dan studi pustaka, sedangkan metode analisis dan perancangan sistem menjelaskan tentang analisis sistem, perancangan sistem (design), implementasi dan pemeliharaan sistem.

\subsection{Metode Pengumpulan Data}

Berikut beberapa proses yang dilalui penulis dalam pengumpulan data guna membantu penulis dalam menyusun penelitian ini, yaitu :

1. Metode observasi

Pengumpulan data dan informasi dengan cara meninjau dan melakukan pengamatan secara langsung terhadap kegiatan yang sedang dilakukan di PT. Kerta Gaya Pusaka, 
pengenalan data yang ada sehingga dapat diadakan evaluasi dari sudut kelayakanjudul dan problematika masalah dalam penelitian.

2. Metode Studi pustaka

Penulis melakukan studi pustaka sebagai bahan tambahan guna melengkapi kekurangan-kekurangan data yang diperoleh dari wawancara dan observasi. Pengumpulan data dengan cara mengambil dari sumber-sumber media cetak maupun elektronik yang dapat dijadikan acuan dalam pembuktian pembahasan masalah dalam penelitian ini.

\subsection{Metode Analisis dan Perancangan Sistem}

\subsubsection{Analisis Sistem}

Analisis Sistem suatu metode yang saya gunakan untuk menganalisa bagaimana sistem pengiriman paket dan dokumen, mengetahui jumlah biaya pengiriman dan cek nomor resi, bagaimana cara menyampaikan informasinya kepada pelanggan atau pengunjung.Untuk memperoleh kesimpulan dengan jelas dan lebih spesifik sehingga membantu dalam desain sistem informasi yang lebih baik. Analisis juga dilakukan untuk mengetahui sistem informasi yang dibuat dapat membantu dalam pengembangan.

\subsubsection{Perancangan Sistem (Design)}

Pada perancangan sistem informasi pengiriman barang dan dokumen ini menggunakan aliran data seperti context diagram dan DFD serta menggambarkan relationship hubungan dari sistem keseluruhan. Database design merupakan tabel yang akan mengisi baris data. Sedangkan desain grafik meliputi sistem informasi struktur dan sistem informasi antar muka input dan output. Sistem informasi ini menggunakan Database MySQL dan PHP.

\subsubsection{Implementasi}

Tahap implementasi yang saya gunakan mengambil cara kerja dan penggunaan sistem secara keseluruhan dan dilengkapi dengan hasil tampilan program saat dijalankan beserta segmen program, penulisan program dan instalasi.cara menyampaikan informasinya kepada pelanggan atau pengunjung. 


\subsubsection{Pemeliharaan Sistem (Maintenance )}

Tahap pemeliharaan sistem tahap yang dilakukan setelah tahap implementasi yang meliputi pemakaian saat penggunaan, audit sistem, penjagaan, perbaikan, dan peningkatan sistem. Perawatan dimaksudkan agar sistem yang telah diimplementasikan dapat mengikutiperkembangan dan perubahan apapun yang terjadi guna meraih penggunanya.

\subsection{Sistem Informasi}

Sistem Informasi adalah suatu sistem di dalam suatu organisasi yang mempertemukan kebutuhan pengolahan transaksi harian, mendukung operasi, dan kegiatan strategi dari suatu organisasi dan menyediakan pihak luar tertentu dengan laporan-laporan yang diperlukan. [5]

Sistem informasi adalah sistem yang berisi SPD (Sistem Pengolahan Data) yang dilengkapi dengan kanal-kanal komunikasi yang digunakan dalam sistem organisasi data". Berdasarkan definisi di atas penulis dapat menyimpulkan bahwa sistem informasi adalah sistem pengolahan data dalam suatu organisasi yang bersifat manajerial. [6].

\subsection{Sistem Informasi Berbasis Web}

Sistem informasi berbasis web merupakan sistem yang dalam bentuknya berupa website. Menggunakan dan memerlukan akses koneksi internet dan browser untuk dapat mengoperasikan. Sistem informasi berbasis web sering disebut sebagai situs internet. Dalam pembuatan situs harus mempunyai tujuan yang jelas untuk apa tujuan itu yang jelas untuk apa tujuan itu dibuat. Jenis-jenis situs dikelompokkan sesuai dengan tujuan adalah sebagai berikut ini : 1. Marketing Tool -"Marketing tool is the techniques and materials used by those who are involved in the promotion of goods and services." Artinya alat pemasaran merupakan teknik dan bahan yang digunakan oleh orang-orang yang terlibat dalam promosi dari barang dan jasa. Marketing tools merupakan situs web yang dibuat dengan tujuan untuk mempromosikan suatu produk atau jasa pelayanan yang ada pada suatu perusahaan atau dapat berupa company profile. Pemasaran melalui media internet akan lebih cepat dan jangkauannya lebih luas".2.b.E-Commerce (Electronic Commerce). E-Commerce "adalah penggunaan jaringan komputer untuk 
melakukan komunikasi bisnis dan transksaksi komersial. Kemudian di website ECommerce Net, E-Commerce didefinisikan sebagai kegiatan menjual barang dagangan dan/atau jasa melalui internet. Seluruh komponen yang terlibat dalam bisnis praktis diaplikasikan disini, seperti customer service, produk yang tersedia, cara pembayaran, jaminan atas produk yang dijual, cara promosi dan sebagainya”.

\section{HASIL DAN PEMBAHASAN}

\subsection{Perancangan Sistem}

\subsubsection{Conteks Diagram}

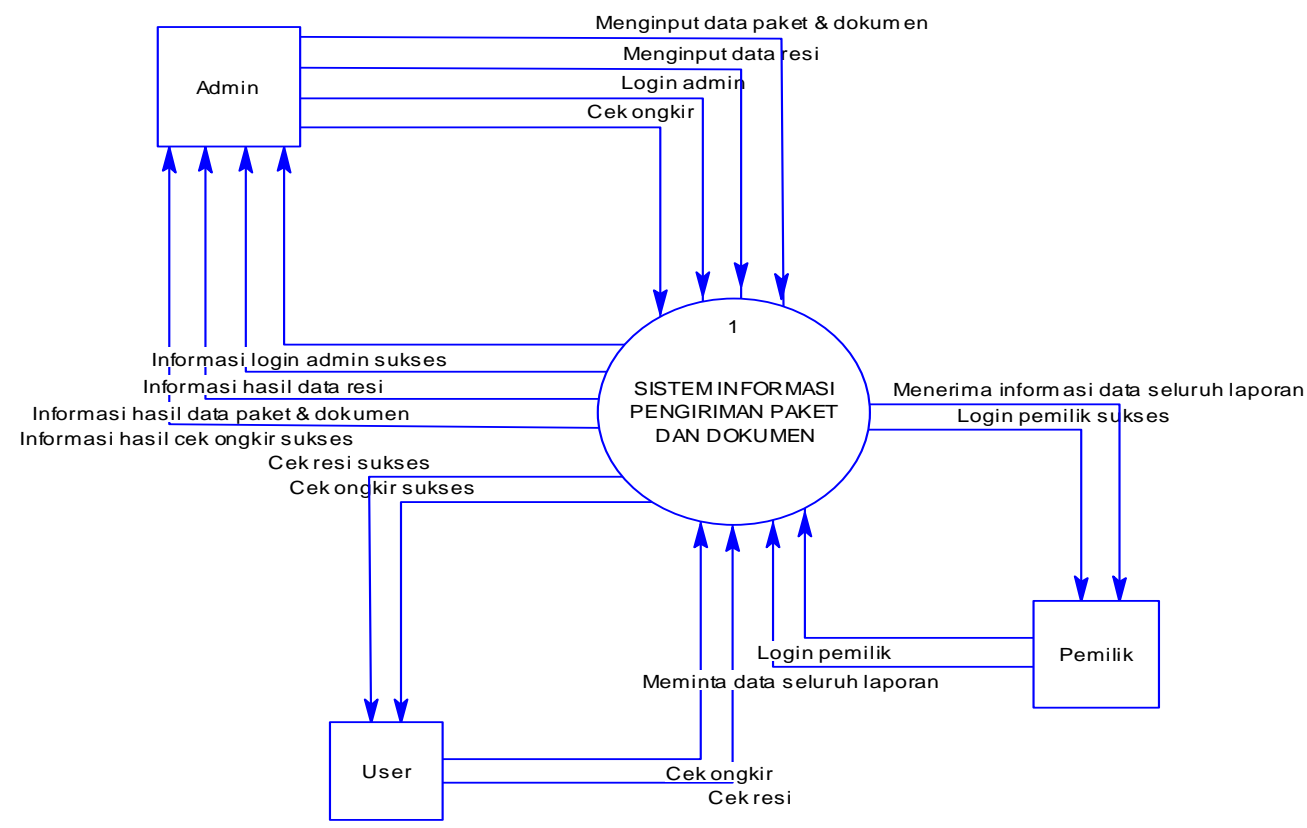

Gambar 3.1. Context Diagram

Untuk memahami bagaimana sistem dibangun maka pada diagram konteks dibawah ini akan menggambarkan sebuah proses aliran dari dari suatu sistem dengan banyak entitas dengan beberapa masukan menjadi input dan output.. Dan diagram konteks adalah sebuah gambaran awal dari sebuah proses data yantar entitas satu dengan entitas yang lainnya dari suatu sistem informasi yang menampilkan aliran data yang mudah dipahami. Dan berikut ini dapat dilihat melalui konteks diagram seperti di bawah ini :

a. Dari context diagram pada gambar 1 dapat dijelaskan bahwa admin dapat melakukan login admin dan mendapatkan login admin sukses. Admin juga dapat mengniputkan 
informasi logistic seperti menginputkan data resi, mengecek biaya pengiriman, dan menginputkan data pengiriman paket dan dokumen. Selanjutnnya dari sistem laporan yang diterima admin adalah admin mendapatkan hasil data seperti data resi, data ongkir sukses, data penerima.

b. User mendapatkan informasi dari biaya pengiriman dan cek resi. Selanjutnya dari sistem kepada pelanggan memberikan informasi biaya pengiriman dan informasi resi pengiriman.

c. Sedangkan pemilik dapat melakukan login pemilik dan mendapatkan login pemilik sukses. Selanjutnya pemilik dapat meminta data seluruh laporan dari admin. Selanjutnya pemilik menerima data seluruh laporan dari sistem yang telah di kelola oleh admin.

\subsubsection{Data Flow Diagram}

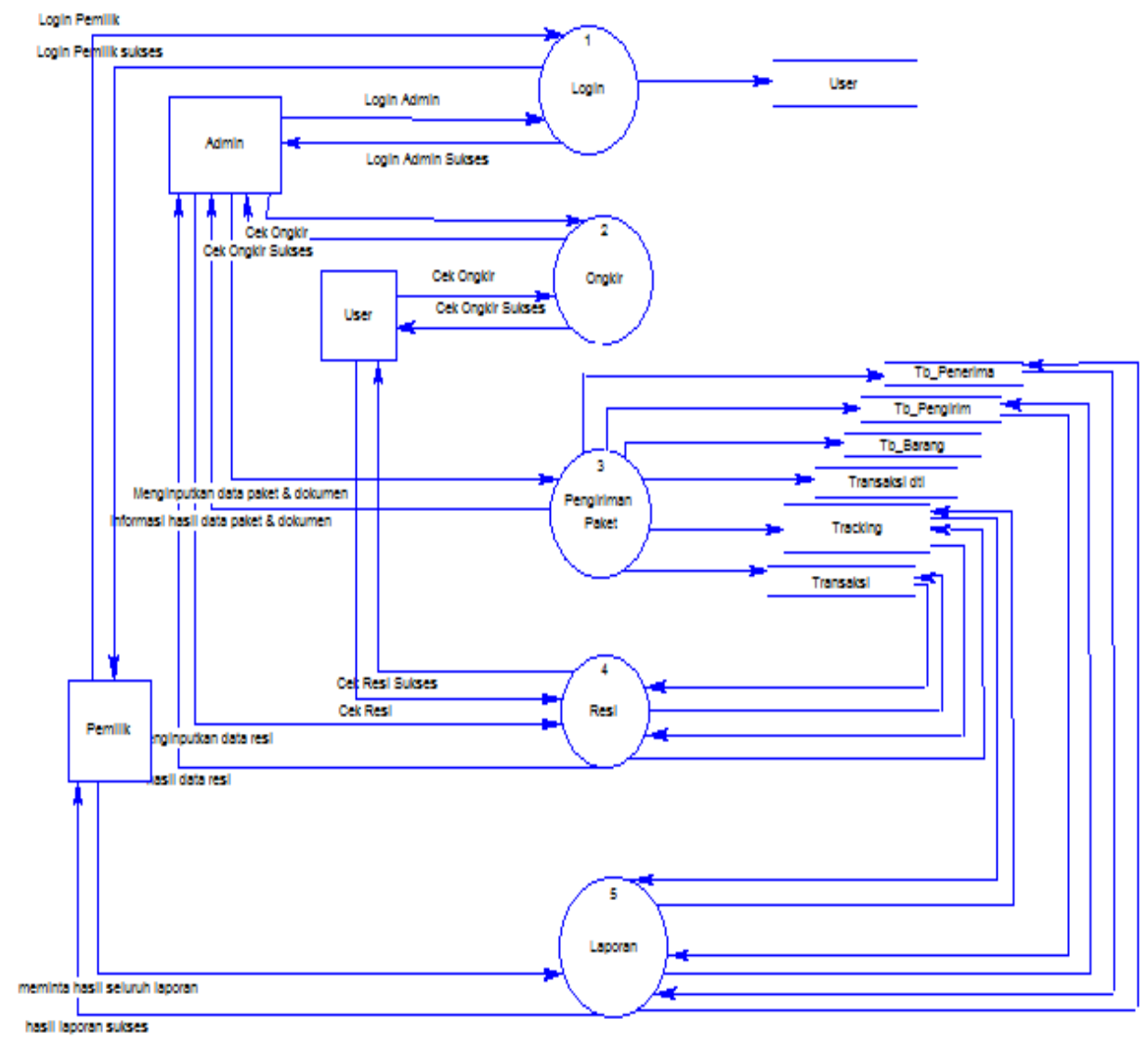

Gambar 3.2. Data Flow Diagram 
Untuk memahami bagaimana sistem dibangun maka berikut ini adalah data flow diagram yang memiliki fungsi sebagai aliran data dari berbagai proses oleh banyak entitas. Pada data flow diagram memiliki fungsi proses data yang terhubung antara satu dengan yang lain. Data flow diagram merupakan aliran data yang dapat dibaca sebagai petunjuk jalannya suatu sistem dari program yang telah dibuat.

a. Proses 1 Login : Pada proses login dapat di lakukan oleh admin dan pemilik. Selanjutnya admin dan pemilik mendapatkan login sukses.

b. Proses 2 Pengiriman Paket dan Dokumen : Pada proses 2 menerima input dari admin berupa data pengiriman paket dan dokuman kemudian proses 2 akan memberi output kepada admin berupa informasi data pengiriman paket dan dokumen. Proses 2 menyimpan data input dari admin ke dalam beberapa tabel penerima, tabel pengirim, tabel barang, tabel transaksi, tabel transaksi detail, tracking.

c. Proses 3 Cek Ongkir : Pada proses cek biaya pengiriman admin dapat mengecek biaya pengiriman ke proses lalu proses memberikan output kepada admin informasi cek biaya pengiriman. User menginputkan ke proses kota asal, tujuan, berat ke proses untuk mengetahui biaya pengiriman, lalu proses memberikan output kepada user berupa hasil biaya pengiriman.

d. Proses 4 Cek Resi : Pada proses melacak nomor resi admin menginputkan data resi ke proses lalu proses memberikan output ke admin berupa informasi admin sukses, dimana di peroleh tabel transaksi, dan tracking dari pengiriman paket yang di inputkan admin di proses ke proses resi yang mengasikan user dapat melakukan cek resi pengiriman.

e. Proses 5 Mengelola Laporan : Laporan yang akan diberikan kepada pimpinan , proses perlu membacadata dari beberapa tabel, yaitu tabel transaksi, tabel pengirim, tabel penerima.

\subsubsection{Entity Relationship Diagram}

Untuk memahami bagaimana sistem dibangun dapat dilihat melalui data Entity Relationalship diagram seperti di bawah ini 


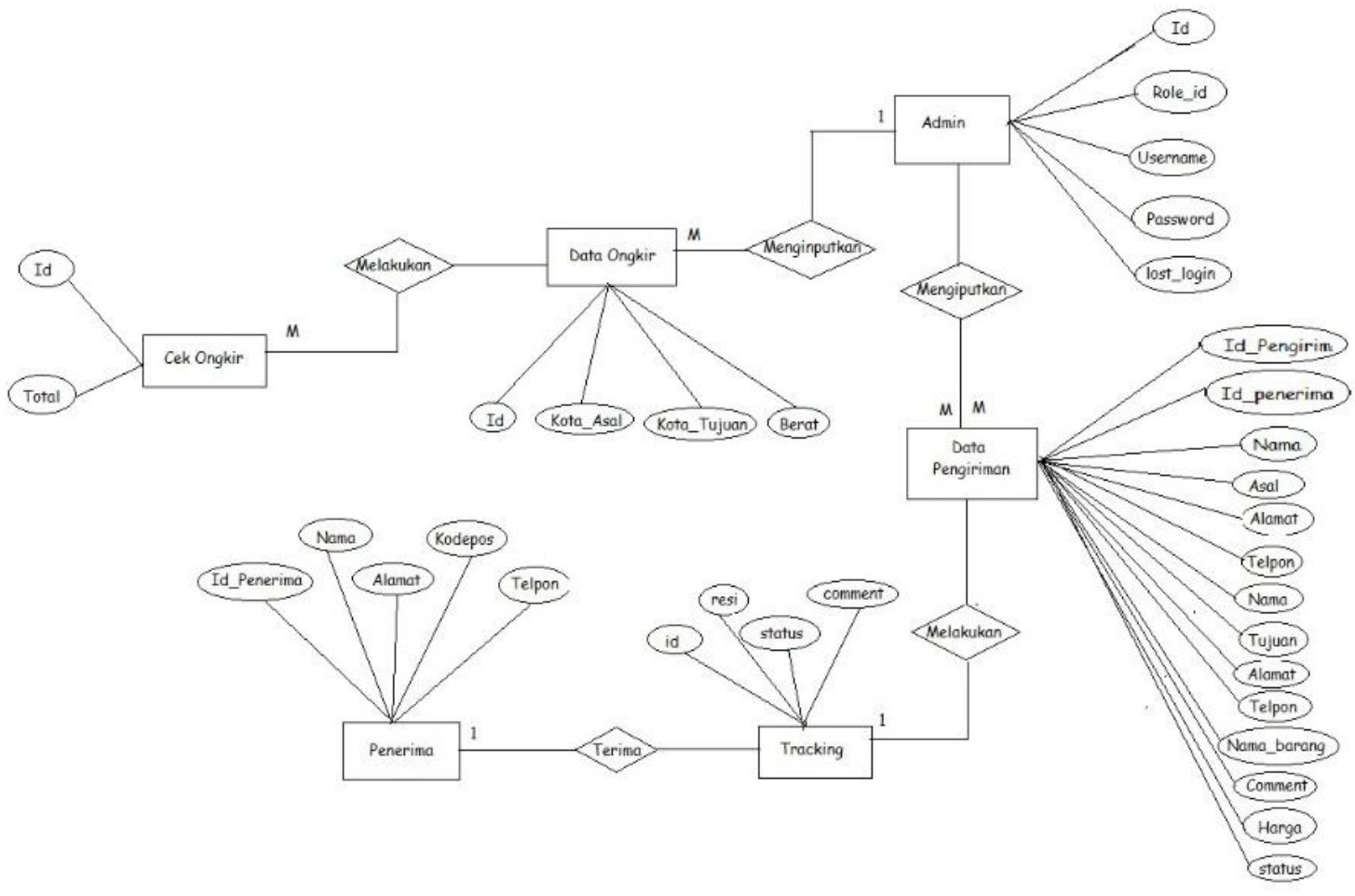

Gambar 3.3. Entity Relationship Diagram

\subsection{Integritas dan Pengujian Sistem}

Pengujian aplikasi ini menggunakan localhost yang terhubung dengan xampp sebagai koneksi antara data local dengan MySQL database. Dan berikut ini hasil dari pengujian aplikasi.

\subsubsection{Halaman Pengunjung}

Sebelum masuk ke sistem pengunjung masuk pada halaman beranda terlebih dahulu. Dimana halaman beranda ini pengunjung dapat mngetahui cek resi pengiriman barang yang telah dikirimkan dan dapat mengetahui cek biaya pengiriman. Berikut merupakan tampilan halaman beranda. 


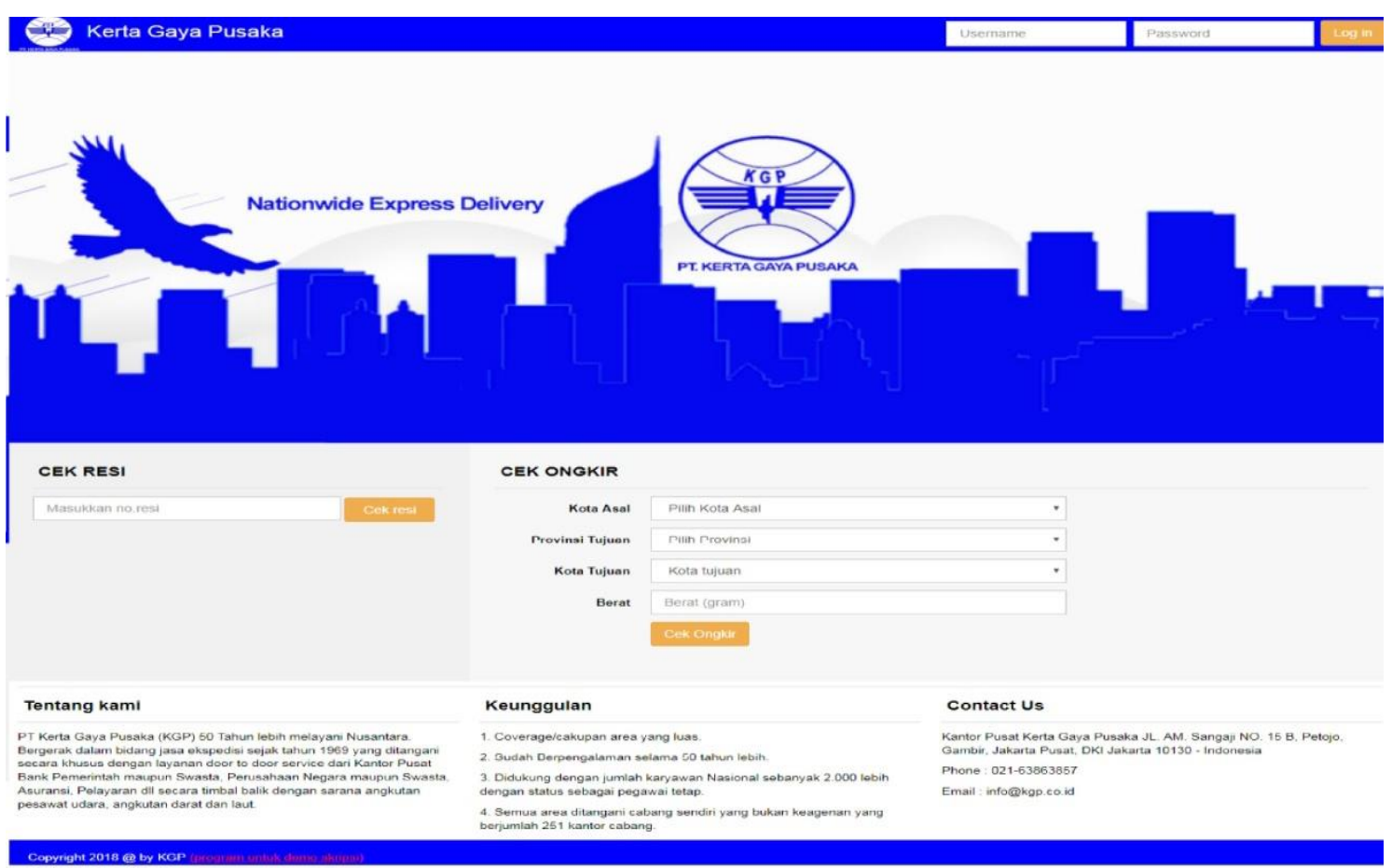

\section{Gambar 3.4. Halaman Pengunjung}

\subsubsection{Halaman Cek Resi}

Pada halaman cek resi pengunjung dapat melakukan cek resi pengiriman untuk mengetahui posisi paket yang dikirimkan apakah sudah sampai tujuan apa belum, dan berikut merupakan halaman cek resi.

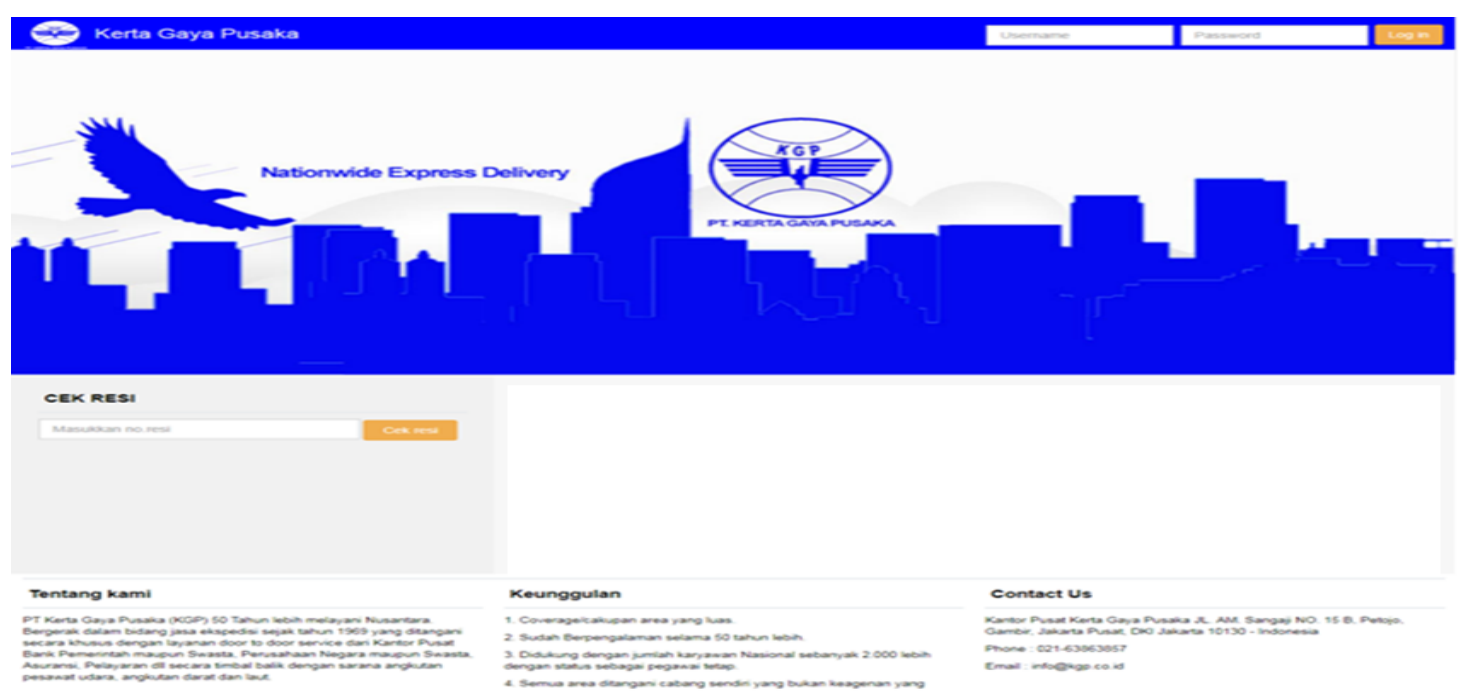

Gambar 3.5. Halaman Cek Resi 


\subsubsection{Halaman Cek Ongkir}

Pada halaman cek ongkir disini pengunjung dapat melihat berapa biaya pengiriman dari kota asal, tujuan dan berat barang dari cek biaya pengiriman yang telah dicari, dan berikut halaman dari cek biaya pengiriman.
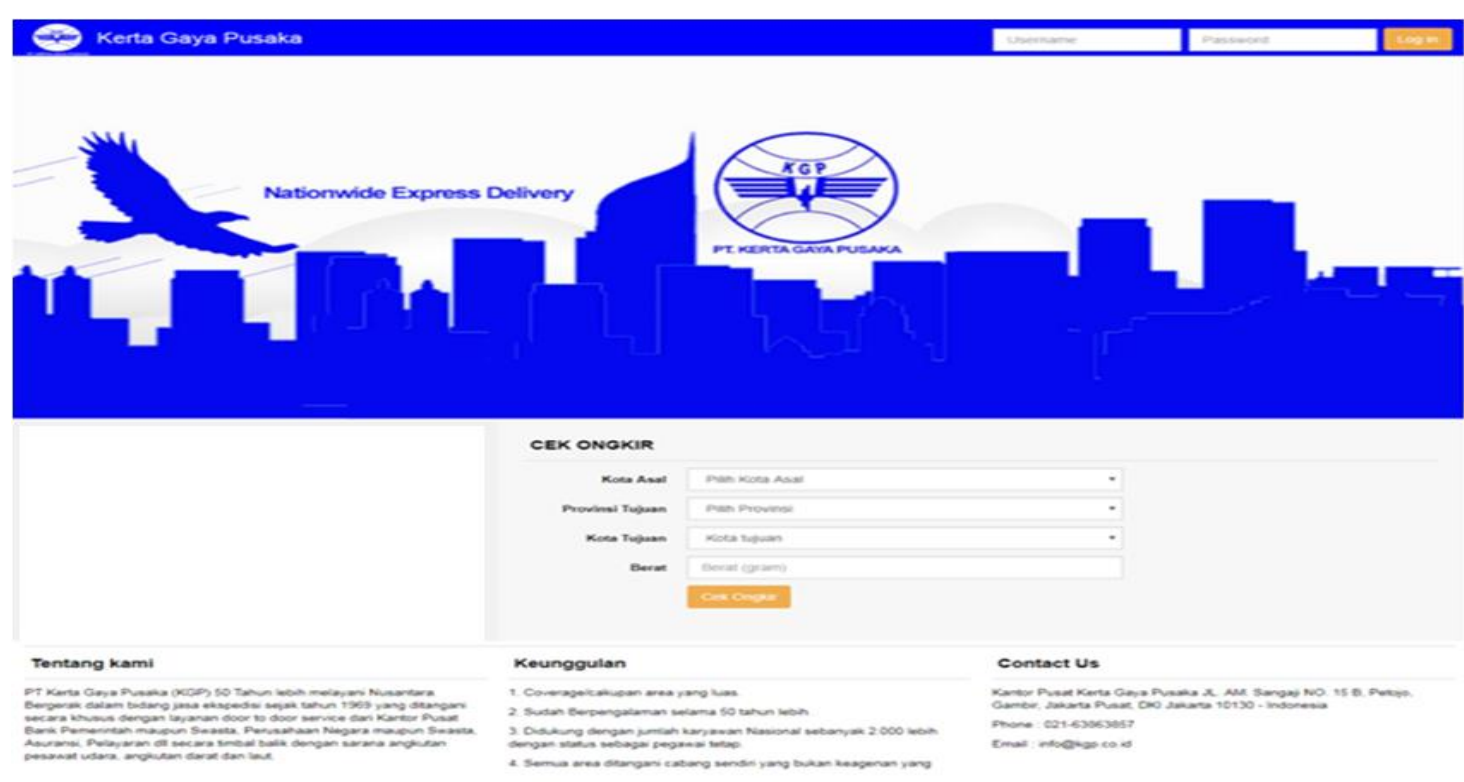

Gambar 3.6. Halaman Cek Ongkir

\subsubsection{Halaman Hasil Cek Ongkir}

Pada halaman hasil cek ongkir dimana pengunjung dapat melihat hasil cek biaya pengiriman dari cek ongkir yang telah dicari melalui inputkan pengunjung kota asal, tujuan, berat barang sehingga muncul hasil biaya pengiriman, dan berikut merupakan halaman dari hasil cek biaya pengiriman.

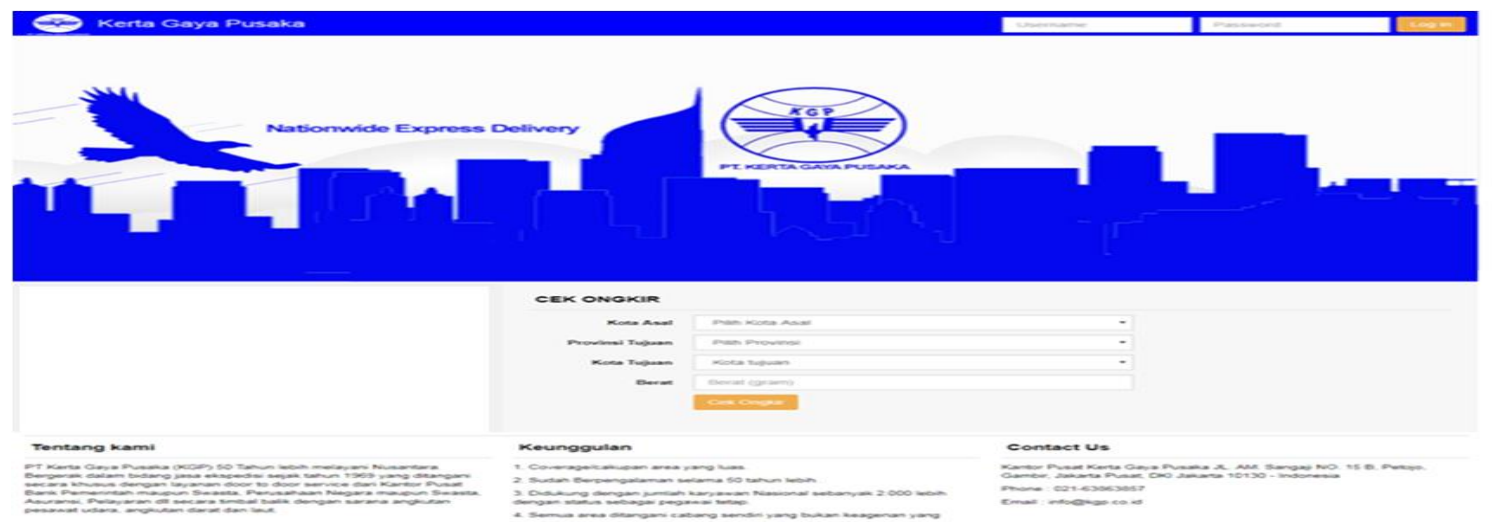

Gambar 3.7. Halaman Hasil Cek Ongkir 


\subsection{Hasil Pengujian}

\subsubsection{Pengujian Dilakukan Oleh User}

Pengujian sistem informasi ini dilakukan oleh user dari data inputan user.

Tabel 3.1 Hasil Uji yang Dilakukan oleh User

\begin{tabular}{|c|l|l|l|}
\hline No & \multicolumn{1}{|c|}{ Skenario } & \multicolumn{1}{c|}{ Hasil yang Diharapkan } & Keterangan \\
\hline 1 & $\begin{array}{l}\text { User menginputkan } \\
\text { nomor resi kemudian } \\
\text { mengklik tombol cek } \\
\text { resi }\end{array}$ & $\begin{array}{l}\text { Sistem menampilkan status } \\
\text { resi pengiriman berdasarkan } \\
\text { nomer resi tersebut }\end{array}$ & Valid \\
\hline 2. & $\begin{array}{l}\text { User menginputkan } \\
\text { kota asal, tujuan, } \\
\text { berat lalu klik tombol } \\
\text { cek ongkir }\end{array}$ & $\begin{array}{l}\text { Sistem menampilkan biaya } \\
\text { pengiriman bedasarankan } \\
\text { kota asal, tujuan dan berat }\end{array}$ & Valid \\
\hline
\end{tabular}

\subsubsection{Pengujian Dilakukan Oleh Admin}

Pengujian sistem informasi ini dilakukan oleh admin untuik mengetahui fungsi input data pengiriman apakah berhasil atau tidak.

Tabel 5. Hasil Uji yang Dilakukan oleh Admin

\begin{tabular}{|c|c|c|c|}
\hline No & Skenario & Hasil yang Diharapkan & Keterangan \\
\hline 1 & $\begin{array}{c}\text { Admin menginputkan data } \\
\text { Login username dan } \\
\text { Paswword lalu klik Login }\end{array}$ & $\begin{array}{c}\text { Sistem menampilkan menu } \\
\text { dashbord. }\end{array}$ & Valid \\
\hline 2. & $\begin{array}{c}\text { Admin lalu mengipnutkan } \\
\text { data pengiriman barang } \\
\text { seperti data pengirim, data } \\
\text { penerima dan data barang. }\end{array}$ & $\begin{array}{c}\text { Admin menghasilkan resi } \\
\text { pengiriman barang yang } \\
\text { akan dicetak }\end{array}$ & Valid \\
\hline 3 & $\begin{array}{c}\text { Lihat resi admin akan } \\
\text { menginputkan nomer resi }\end{array}$ & $\begin{array}{c}\text { Sistem akan menampilkan } \\
\text { detail pengiriman } \\
\text { berdasarkan kode resi } \\
\text { tersebut. }\end{array}$ & Valid \\
\hline 4 & Cetak resi, admin akan & Mencetak detail & \\
& menginputkan nomer resi & $\begin{array}{c}\text { pengiriman berdasarkan } \\
\text { kode pengiriman tersebut }\end{array}$ & \\
\hline
\end{tabular}




\subsubsection{Pengujian Dilakukan Oleh Pemilik}

Pengujian sistem informasi ini dilakukan oleh admin untuik mengetahui fungsi input data pengiriman apakah berhasil atau tidak.

Tabel 6. Hasil Uji yang Dilakukan oleh Pemilik

\begin{tabular}{|c|c|c|c|}
\hline No & Skenario & $\begin{array}{c}\text { Hasil yang } \\
\text { Diharapkan }\end{array}$ & Keterangan \\
\hline 1 & $\begin{array}{c}\text { Pemilik } \\
\text { menginputkan data } \\
\text { Login username } \\
\text { dan Password lalu } \\
\text { klik Login }\end{array}$ & $\begin{array}{c}\text { Sistem menampilkan } \\
\text { menu dashbord. }\end{array}$ & Valid \\
\hline 2. & $\begin{array}{c}\text { Cetak Laporan, } \\
\text { Kilik tombol button } \\
\text { cetak laporan }\end{array}$ & $\begin{array}{c}\text { Mencetak print seluruh } \\
\text { laporan pendapatan } \\
\text { barang yang telah } \\
\text { dikirim }\end{array}$ & Valid \\
\hline
\end{tabular}

\section{KESIMPULAN DAN SARAN}

\subsection{Kesimpulan}

Dari hasil implementasi serta pengujian dan analisa pada sistem ekspedisi pengirman paket dan dokumen di kerta gaya pusaka, maka dapat diambil kesimpulan sebagai berikut

1. Dalam sistem ekspedisi pengiriman paket dan dokumen pada kerta gaya pusaka pelanggan secara langsung dapat melihat jumlah biaya pengiriman dari tujuan tertentu pada website kerta gaya pusaka dengan mudah.

2. Pelanggan dapat memperoleh sistem informasi ekspedisi paket dan dokumen secara online dan sederhana.

3. Pelanggan dapat melacak nomor resi dan melihat keberadaan paket yang telah dikirim.

\subsection{Saran}

Setelah selesai melalui tahapan mulai dari perencanaan, perancangan, penerapan sistem ekspedisi, implementasi dan pengujian, ada beberapa hal yang dapat dilakukan dalam pengembangan program aplikasi sistem ekspedisi online ini, antara lain : 
1. Layanan pada kerta gaya pusaka masih belum menggunakan fitur barcode dalam menambahkan resi pengiriman baru. Kedepan kerta gaya pusaka akan ditambahkan sistem barcode yang akan memudahkan admin dalam melakukan pendataan resi.

2. Pada menu user masih belum memiliki layanan jemput paket. Kedepan kerta gaya pusaka akan ditambahkan menu layanan jemput paket yang akan memudahkan user dalam mengirim paket.

\section{DAFTAR PUSTAKA}

[1]. Jogianto, HM., 2005.Analisa dan Desain Sistem Informasi, Pendekatan Terstruktur, Teori dan Aplikasi Bisnis, hal1, 8, 11, 40, 700. Yogyakarta : Andi Offset.

[2]. Ladjamuddin, ABB., 2005. Manajemen Anlisis dan Desain Sistem Informasi, hal 64, Yogyakarta : Andi Offset.

[3]. Mulyadi., 2009. Sistem Akuntansi,Konsep Pengiriman Barang, Edisi ke 3, hal 5201. Yogyakarta : Salemba Empat.

[4]. Moenir, HAS., 2011. Manajemen Pelayanan Umum di Indonesia, hal 17, 26, 27 Yogyakarta : Bumi Aksara.

[5]. Oetomo., 2011. Tracking System pada Logistik. hal 70. Yogyakarta : Andi Offset.

[6]. Moenir, HAS., 2011. Manajemen Pelayanan Umum di Indonesia, hal 17, 26, 27. Yogyakarta : Bumi Aksara.

[7] Oetomo., 2011. Tracking System pada Logistik, hal 70. Yogyakarta : Andi Offset.

[8] Sutabri, T., 2004. Analisa Sistem Informasi, hal 166. Yogyakarta : Bumi Aksara.

[9]. Tjiptono, F., 2013. Strategi Pemasaran, hal 17. Yogyakarta : Andi Offset

[10]. Witarto., 2008. Memahami Sistem Informasi, Ilmu Komputer Basis Data, Hal 919. Bandung : Informatika.

[11].Fathansyah., 2004. PendekatanBasis Data Pada Sistem Informasi, hal 79, Yogyakarta : Andi Offset.

[12].Bambang, HM., 2010. Analisa dan Desain Sistem Informasi, Pendekatan Terstruktur, Teori dan Aplikasi Bisnis, hal1, 8, 11, 40, 700. Yogyakarta : Andi Offset. 